\title{
Antecedentes dos cursos superiores em Administração brasileiros: as escolas de Comércio e o curso superior em Administração e Finanças
}

\author{
AMON BARROS \\ Fundação Getulio Vargas / Escola de Administração de Empresas de SÃo Paulo, SÃo PaUlo - SP, Brasil
}

\begin{abstract}
Resumo
Este artigo apresenta uma narrativa histórica sobre o desenvolvimento das escolas de Comércio e, posteriormente, do curso superior em Administração e Finanças no Brasil. O estudo derivou de outro trabalho que buscava as origens do curso de Administração da Faculdade de Ciências Econômicas da Universidade Federal de Minas Gerais (FACE/UFMG) e que indicou a importância das escolas de Comércio e do curso superior em Administração e Finanças não apenas para essa faculdade. Foram pesquisados artigos que tratam desses estabelecimentos e desses cursos, bem como elementos da legislação pertinente a ambos. A partir da análise histórica, delineia-se um panorama da estrutura educacional estabelecida no país no período que antecede os primeiros cursos superiores em Administração, criados em 1952. Conclui-se o trabalho reiterando a importância de conhecer as instituições que preexistiram ao Ensino Superior em Administração e apontando a relevância de aprofundar as discussões acerca das formas de transmissão e produção de saberes administrativos no Brasil.
\end{abstract}

Palavras-chave: Escolas comerciais. História da administração. Americanismo. Saberes administrativos.

\section{Background of undergraduate courses in administration in Brazil: the schools of commerce and the higher edu- cation courses in administration and finance}

\begin{abstract}
This paper presents a historical narrative about the development of schools of commerce and higher education courses in Administration and Finance in Brazil that later contributed to the establishment of high education courses in management. The study is an outcome from another work which sought the origins of the undergraduate course in administration at the Faculty of Economic Sciences of the Federal University of Minas Gerais (FACE/UFMG) and indicated the importance of schools of commerce and of the higher education courses in administration and finances and not only for that faculty. Articles on similar institutions and their courses, as well as elements of the relevant legislation were used as primary and secondary data sources. From the historical analysis, an overview of the educational structure in the country is presented, focusing on the period before the first undergraduate courses in administration were created in 1952. The work reiterates the importance of understanding the institutions that pre-existed higher education in administration and indicated the relevance of deepening discussions on the transmission and production of knowledge in Brazil.
\end{abstract}

Key Words: Schools of Commerce. History of administration. Americanism. Knowledge in administration.

\section{Antecedentes de los cursos de grado en Administración brasileños: las escuelas de comercio y el curso de grado en Administración y Finanzas}

\section{Resumen}

Este artículo presenta una narrativa histórica acerca del desarrollo de las escuelas de Comercio y más tarde del curso de grado en Administración y Finanzas en Brasil. El estudio se deriva de otro trabajo que buscaba los orígenes del curso de Administración de la Facultad de Ciencias Económicas de la Universidad Federal de Minas Gerais (FACE/UFMG) y que indicó la importancia de escuelas de Comercio y del curso de grado en Administración y Finanzas no sólo para esta facultad. Se realizaron búsquedas de artículos que tratan estos establecimientos y estos cursos, así como elementos de la legislación pertinente para ambos. A partir del análisis histórico, se esboza una visión general de la estructura educativa establecida en el país en el período antes de los primeros cursos de grado en Administración, creados en 1952 . Se concluye el trabajo reiterando la importancia de conocer las instituciones que existían antes de la Enseñanza Superior en Administración e indicando la relevancia de profundizar las discusiones sobre las formas de transmisión y producción de saberes administrativos en Brasil.

Palabras clave: Escuelas comerciales. Historia de la administración. Americanismo. Saberes administrativos. 


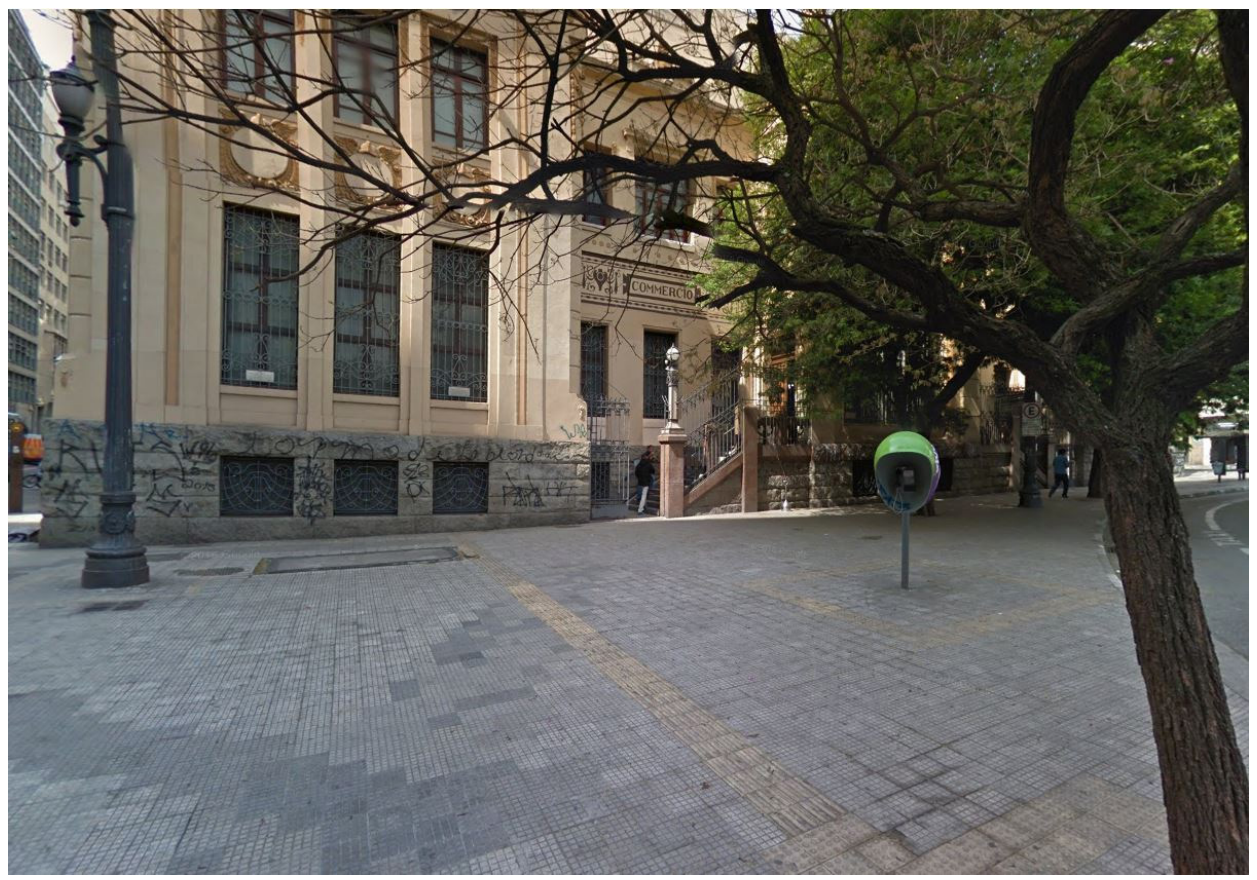

\section{CONSIDERAÇÕES INICIAIS}

Antes dos bacharelados em Administração (e Contabilidade ou Economia) se estabelecerem no Brasil, as escolas de Comércio e o curso superior em Administração e Finanças desempenharam papel importante na formação de pessoas que se dedicavam a administrar negócios públicos e privados. Dada a relevância desses estabelecimentos de ensino e cursos na primeira metade do século XX e seu papel na disseminação de saberes administrativos, chega a ser surpreendente o quão pouco é dito sobre eles.

As escolas de Comércio receberam pouca atenção nos trabalhos que abordam o desenvolvimento da área de Administração, com exceção dos estudos de Nicolini (2003), Coelho (2006) e Coelho e Nicolini (2014). Isso talvez aconteça porque, especialmente após a disseminação dos bacharelados em Economia, Contabilidade e Administração e a reforma do Ensino Médio no governo militar, as escolas de Comércio perderam importância no cotidiano brasileiro. Esse obscurecimento privilegia certas formas de escrever a história, destacando determinados atores e narrativas em detrimento de agentes 'menos interessantes'.

Contudo, sua relevância histórica é maior do que a atenção recebida. O desenvolvimento das escolas de Comércio e, posteriormente, dos cursos superiores em Administração e Finanças, faz parte da trajetória específica do desenvolvimento da Administração no Brasil, enquanto saber. Estes constituíram, respectivamente, ponto de partida e momento transitório nas formas que a transmissão desses conhecimentos assumiu no país ao longo dos anos. Assim, contribuíram para disseminar interpretações do que seria a Administração e suas práticas. "Os saberes da administração circulavam em diferentes níveis educacionais" (PETINELLI-SOUZA, 2013, p. 475) e atendiam a interesses de diversas camadas da população.

Ao refletir sobre esses estabelecimentos de ensino e sobre o curso de Administração e Finanças é possível compreender o desenvolvimento do ensino em Administração no Brasil, ampliando as narrativas que partem do estabelecimento dos cursos superiores (ALCADIPANI e BERTERO, 2012; BARROS e CARRIERI, 2013; FISCHER, 1985). Neste artigo, apresenta-se uma narrativa sobre o desenvolvimento tanto das escolas de Comércio quanto do curso superior em Administração e Finanças.

\footnotetext{
* Fonte da imagem: Google maps. Disponível em: <https://goo.gl/maps/CnPxkBk43aT2>. Acesso em 19 jan. 2017.
} 
Afirma-se que o ensino de Administração no país preexistia à criação dos primeiros cursos superiores na década de 1950 e à chegada do apoio estadunidense. A análise concentra-se nos cursos e estabelecimentos de ensino reconhecidos oficialmente e na legislação que os regula. Ainda que tal enfoque arrisque refletir a história oficial, ele é suficiente para delinear uma panorâmica do campo.

A fim de discutir os efeitos dessa estrutura no desenvolvimento dos saberes administrativos no Brasil, este artigo se divide em três seções, além desta introdução. As escolas de Comércio e seu desenvolvimento são discutidos, ressaltando a importância dessa modalidade de ensino até a primeira metade do século XX. Em seguida, aborda-se o curso superior em Administração e Finanças, ligado ao desenvolvimento das escolas de Comércio. Essa iniciativa frustrada para o ensino da Administração estabeleceu formalmente o Ensino Superior na área. Por fim, são apresentadas conclusões e são indicados futuros caminhos de pesquisa, ressaltando a importância de entender o cenário brasileiro para que se possa ter maior clareza sobre os caminhos da Administração no Brasil.

\section{DO CAMINHO PERCORRIDO}

O interesse pelas escolas de Comércio emergiu durante a elaboração de uma pesquisa sobre o curso de graduação em Administração da Faculdade de Ciências Econômicas da Universidade Federal de Minas Gerais (FACE/UFMG). Durante o manuseio dos documentos ligados à instituição de ensino, pôde-se perceber a importância que tiveram os professores de duas escolas de Comércio na criação da primeira faculdade de Economia de Minas Gerais, que, posteriormente, abrigou alguns dos primeiros cursos em Administração do país.

A partir dessas pistas, aprofundou-se a compreensão dos aspectos históricos das escolas de Comércio por meio da leitura dos regulamentos que regiam o funcionamento desses estabelecimentos de ensino. Foram consultadas as legislações digitalizadas e disponibilizadas on-line, pertinentes à regulamentação dos cursos abordados. Parte delas era referenciada nos arquivos da FACE/UFMG, consultados durante a elaboração do trabalho. Coincidentemente, a pesquisa foi realizada próximo à comemoração de setenta anos da faculdade, o que facilitou o acesso a fontes primárias importantes para entender o percurso da FACE/UFMG e, consequentemente, das escolas comerciais e do curso de Administração e Finanças.

Contudo, como coloca Foucault (2008), todo 'documento é monumento' e, nesse sentido, a análise da legislação que versa sobre o tema dá uma visão apenas parcial do objeto estudado. Assim, a análise foi complementada com a busca por dados secundários na literatura que versa tanto sobre as escolas comerciais quanto sobre a história de alguns estabelecimentos específicos. A pesquisa bibliográfica nas bases de dados Spell e Scholar permitiu mapear os trabalhos que discutiam as escolas de Comércio e o surgimento dos primeiros cursos superiores associados a elas. Foram identificados poucos artigos acadêmicos que abordassem diretamente a importância do ensino comercial.

Este trabalho dialoga especialmente com duas correntes de discussão nos estudos organizacionais: estudos que aproximam a Administração e a História, em um movimento que foi denominado historic turn e que impactou especialmente os estudos organizacionais (KIPPING e ÜSDIKEN, 2014; ROWLINSON, 2013; COSTA, BARROS e MARTINS, 2010; FERREIRA, 2009; CLARK e ROWLINSON, 2004). A aproximação entre esses campos do saber contribui para o estabelecimento de um olhar reflexivo sobre a Administração (ÜSDIKEM e KIESER, 2004; ROWLINSON, JACQUES e BOOTH, 2009).

O texto flerta também com a perspectiva pós-colonial ou decolonial que, embora diferentes entre si, almejam iluminar as condições de subalternidade impostas à construção do saber e aos povos 'às margens' dos centros econômicos de produção de conhecimento (WANDERLEY, 2015; IBARRA-COLADO, 2006; ALCADIPANI e CALDAS, 2012). Essa interação se estabelece na medida em que se busca revisitar um passado obscurecido pela expansão da Administração, muitas vezes lido exclusivamente a partir do importante viés do americanismo (FRENKEL, 2009; ÜSDIKEN, 1997).

Em outras palavras, o americanismo é uma peça-chave para entender a expansão do management como elemento inserido no interior de disputas de poder econômicas e geopolíticas, mas essa expansão se dá na relação com agentes locais (FRENKEL e SHENHAV, 2003; FRENKEL, 2009; ÜSDIKEN, 2004). Dessa maneira, associa-se a outros textos que trataram das transformações do cenário do ensino em Administração em diversos países antes e após a influência estadunidense (p. ex., LOCKE, 1989; ÜSDIKEM e ÇETIN, 2001; KIPPING, ÜSDIKEM e PUIG, 2004; KIPPING, ÜSDIKEM e ENGWALL, 2008). 


\section{AS ESCOLAS DE COMÉRCIO}

A educação comercial e a educação superior principiaram no Brasil após a chegada da família real, em 1808. A transferência da capital do império português para o Rio de Janeiro contribuiu para que a economia brasileira se tornasse mais complexa, tendo que suprir demandas anteriormente inexistentes. Ainda em 1808 foi criada a cadeira de Economia Política no Rio de Janeiro e, no ano seguinte, foram introduzidas Aulas de Comércio (PELEIAS, SEGRETI, SILVA et al., 2007). Em 1856, as aulas de comércio foram substituídas pelo Instituto Comercial do Rio de Janeiro, que deu início ao ensino sistemático de técnicas comerciais no país. Já na segunda metade do século XIX se discutia o estabelecimento de um curso superior voltado à administração da coisa pública (COELHO e NICOLINI, 2014).

O ensino comercial se institucionalizou definitivamente em 1905, quando foram decretadas como instituições de utilidade pública a Academia de Comércio do Rio de Janeiro, indicada como modelo para suas congêneres, e a Academia de Comércio de Juiz de Fora (PELEIAS, SEGRETI, SILVA et al., 2007). A Escola Prática de Comércio, de São Paulo (atualmente nomeada Fundação Escola de Comércio Álvares Penteado), fundada em 1902, também recebeu reconhecimento estatal.

A instituição carioca oferecia o Curso Geral, que formava técnicos em guarda-livros e perito judicial. O curso habilitava para empregos no Ministério da Fazenda, além de permitir que os candidatos prosseguissem estudos no Ensino Superior para formação de agentes consulares, atuários e contadores-chefe (CASTRO, 1991). Havia um curso superior, nos termos da época, mas seus egressos não recebiam o título de bacharel, restrito aos graduados em Direito, Engenharia e Medicina. Essa situação foi alterada em 1931, com o Decreto n. 20.158 (BRASIL, 1931), que estabeleceu o ensino comercial como opção de Ensino Médio profissionalizante e como curso superior (ANDREOTTI, 2006).

Alunos do ensino comercial e, também, do ensino normal, industrial e agrícola tinham restringidas suas possibilidades de acesso ao Ensino Superior (BRITO, 2006). Os cursos que poderiam ser frequentados pelos egressos dessas modalidades de Ensino Médio eram restringidos em acordo com a legislação da época. Egressos dos cursos técnicos de comércio eram os únicos que poderiam obter formação superior na respectiva área. Entretanto, eles não poderiam seguir seus estudos em outros cursos superiores. A obtenção do diploma de nível superior na área comercial facultava o acesso a cargos médios no serviço público ou o exercício da função de contador, o que, em geral, indicava ascensão social, ainda que modesta. O modelo brasileiro era inspirado no alemão, que mantém diferenças claras entre o ensino técnico superior e o ensino universitário e segrega os alunos entre os que seguiram uma ou outra formação (SANSON, 2004).

Comentando o desenvolvimento dos cursos no Brasil, Souza (2006, p. 380) afirma que em 1907 havia 14 estabelecimentos registrados, com 155 docentes e 970 alunos matriculados (60 diplomados). Em 1942, havia 721 escolas, com 5.316 professores registrados, 67.672 alunos matriculados e 13.871 diplomados. Como fatores que contribuíram para que tais escolas se disseminassem, Cintra (2009) destaca a ampliação do comércio como efeito da diversificação e fortalecimento da economia do país.

Novas configurações sociais que se estabeleceram com a tomada do poder por Getúlio Vargas em 1930 "demandavam a preparação de recursos humanos, na forma de técnicos e tecnólogos de várias especializações, assim como métodos de trabalho mais sofisticados" (NICOLINI, 2003, p. 7). A necessidade de formação de quadros tecnicamente capacitados constituiu outro elemento relevante para o estabelecimento do ensino de Administração no Brasil. A demanda por pessoas aptas a ocupar posições no Estado contribuiu para a elaboração de políticas buscando o desenvolvimento do ensino comercial. Essas políticas ganharam maior espaço no governo de Getúlio Vargas (CINTRA, 2009). Nesse sentido, Coelho (2006, p. 12) afirma que "[n]o ensino secundário o estudo de AP [Administração Pública] se deu implicitamente na instrução profissional das 'artes e ofícios' comerciais, da qual funcionários públicos e pretendentes a tal cargo se fizeram valer". O autor afirma, ainda:

[...] nesse ensino prevalecia uma concepção mecanicista - de organizações e métodos (O\&M) - que equiparava a repartição pública à organização privada. É essa concepção mecanicista - com modificações e aperfeiçoamentos, evidentemente - que despontará no Brasil em meados dos anos trinta por efeito do aporte das ideias da escola clássica da administração no país (COELHO, 2006, p. 13).

O modelo de ensino que durou até 1931 mantinha a relação de subordinação entre os cursos superiores. Direito, Medicina e as Engenharias eram cursos distintos e frequentados por pessoas oriundas dos estratos de renda mais elevada, que obtinham diplomas mais valorizados. Isso contribuía para que os egressos tivessem e mantivessem posição de dominância na 
sociedade. Por sua vez, os cursos comerciais atendiam principalmente pessoas de renda intermediária ou baixa, que conquistariam dali posições de nível técnico ou operacional no serviço público ou em empresas privadas (SANSON, 2004), servindo como garantia de manutenção desse nível de renda. O ensino técnico comercial, o industrial e o agrícola não eram frequentados pelos membros das elites dirigentes do país, mas por grupos urbanos que experimentavam ascensão econômica.

O desenvolvimento das escolas de Comércio está ligado ao posterior estabelecimento do ensino nos cursos superiores de Economia, Contabilidade e Administração. Especialmente até 1961, com a aprovação da Lei de Diretrizes e Bases (LDB) (BRASIL, 1961), o ensino no Brasil tinha caráter dualista. Cursos básicos e médios preparavam os alunos para o mercado de trabalho, enquanto o ensino propedêutico era destinado a grupos abastados e visava a permitir o acesso aos bacharelados.

Em 1943, com a chamada Lei Orgânica do Ensino Comercial (BRASIL, 1943), editada pelo ministro Gustavo Capanema, dois ciclos de ensino foram criados, sendo que o segundo se subdividia em cinco cursos comerciais técnicos:

Art. 4o O primeiro ciclo do ensino comercial compreenderá um só curso de formação: o curso comercial básico.

Parágrafo único. O curso comercial básico, que terá a duração de quatro anos, destinar-se-á a ministrar os elementos gerais e fundamentais do ensino comercial.

Art. 5 o 0 segundo ciclo do ensino comercial compreenderá cinco cursos de formação, denominados cursos comerciais técnicos:

1. Curso de comércio e propaganda.

2. Curso de administração.

3. Curso de contabilidade.

4. Curso de estatística.

5. Curso de secretariado.

Parágrafo único. Os cursos comerciais técnicos, cada qual com a duração de três anos, são destinados ao ensino de técnicas próprias ao exercício de funções de caráter especial no comércio ou na administração dos negócios públicos e privados.

Na nova formatação o curso comercial básico (técnico) tinha pelo menos 4 anos de duração e poderia ser atendido por pessoas com mais de 11 anos de idade, mediante exame de admissão, obtendo ao final o Diploma de Auxiliar de Escritório (GOMES JÚNIOR, 2013). O egresso dos cursos técnicos poderia "ingressar em estabelecimento de ensino superior, para matrícula em curso diretamente relacionado com o curso comercial técnico concluído" (BRASIL, 1943). Castro (1991) reitera que, ao estabelecer tais divisões, o ministro Gustavo Capanema tinha em mente a separação dos cursos superiores. Capanema previa a "criação da Faculdade Nacional de Administração (FNA), que substituiria a Faculdade de Economia da Universidade do Brasil" (CASTRO, 1991, p. 24). Os cursos que fariam parte dessa faculdade seriam os de "Administração Pública, Administração Econômica, Contabilidade, Estatística, Atuária, Biblioteconomia e Arquivismo, Museologia e Jornalismo" (CASTRO, 1991, p. 24).

Contudo, "o curso de Administração Econômica concederia o grau de bacharel em Ciências Econômicas" (CASTRO, 1991, p. 24) e não de bacharel em Administração, o que mostra que esses cursos se encontravam imbricados, com suas diferenças pouco definidas. Outra proposta, datada de 1942, propunha a criação de três cursos na FNA: Ciências Sociais e Diplomacia, Administração e, por fim, Economia e Finanças, que, possivelmente, implicaria a concessão de diplomas diferentes para cada egresso.

Nenhuma dessas ideias se efetivou e apenas em 1945 um novo decreto-lei passou a regular os cursos superiores vinculados ao ensino técnico comercial (BRASIL, 1945). Em seu artigo $4^{\circ}$, observa-se que o concluinte de cursos comerciais técnicos poderia ser admitido nos cursos de Ciências Econômicas ou de Ciências Atuariais. Os cursos comerciais de nível técnico continuaram a ser regulados pela Lei Orgânica do Ensino Comercial (BRASIL, 1943).

Após o período do Estado Novo foram estabelecidas mudanças que permitiam que os estudantes que frequentavam o ensino básico ou estabelecimentos de ensino comercial ingressassem nos cursos clássicos ou científicos, desde que complementassem seus estudos. 
Em 1950, a Lei 1.076 flexibiliza o ingresso dos estudantes concluintes do primeiro ciclo dos ensinos industrial, comercial e agrícola a ingressarem no curso clássico ou científico seguindo algumas exigências de complementação de disciplinas. A Lei 1.826/1953 facultava o direito de ingresso em qualquer curso superior a todos que tivessem concluído o curso técnico em qualquer dos ramos de ensino observando-se exames de adaptação. Surge pela primeira vez uma possibilidade de aproximação entre o ramo secundário propedêutico e os cursos profissionalizantes de nível médio (CANALI, 2009, p. 11).

Afora a possibilidade dos egressos complementarem seus cursos, as bases do ensino técnico comercial instituídas em 1943 permaneceram mesmo após a LDB, de 1961. Para Carvalho (1965 apud PERES, 2014) o período que vai até o ano de 1971 é o ápice do ensino comercial no Brasil, contando com cerca de 270.000 alunos distribuídos entre 1.423 estabelecimentos de ensino em 1964. Segundo Peres (2014), o ensino comercial começou a declinar após a reforma do ensino, de 1971. Além disso, é possível que a regulamentação da profissão de técnico de administração, em 1967, tenha estabelecido os contornos da profissão liberal 'de nível superior' e contribuído para a diminuição dos cursos técnicos de nível médio (BRASIL, 1967).

Castro (1991) e Peleias, Segreti, Silva et al. (2007) afirmam que os cursos de Contabilidade, Economia e Administração se desenvolveram em parte a partir das bases construídas nos estabelecimentos que ministravam o ensino comercial. Contudo, o primeiro curso superior que surge para atender à demanda por formação superior é o de 'Administração e Finanças'. Assim, a próxima seção aborda o desenvolvimento do Ensino Superior nas áreas de Economia, Contabilidade e Administração, com ênfase nestas, deixando de lado outros desenvolvimentos, como o curso superior de Secretariado e o curso superior de Publicidade e Propaganda.

\section{O CURSO SUPERIOR DE ADMINISTRAÇÃO E FINANÇAS E O ESTABELECIMENTO DO ENSINO SUPERIOR EM ADMINISTRAÇÃO NO BRASIL}

No Brasil do século XIX, o ensino de Economia e Administração se dava, principalmente, nos cursos de Direito, como os de Olinda e São Paulo (SANSON, 2004; PAULA, 1991). A "emancipação da ciência econômica, sua conformação como corpo doutrinário específico é processo que se dá durante o século XIX. Até então, as preocupações com os problemas econômicos são parte do que se chamava Filosofia Moral" (PAULA, 1991, p. 24). As ciências econômicas só se constituem como campo específico no Brasil no século XX, tanto na forma de Economia Política, como na forma de Administração Pública e de empresas.

Até o primeiro governo de Getúlio Vargas, a abordagem em relação ao ensino que formasse administradores públicos se dava especialmente a partir da lógica de observância do quadro legal (KEINERT, 1994). Essa visão de administração enquanto observância da norma pode também ser resultado da falta de consolidação dessa área do saber (PAULA, 1991). A ótica jurídica se fez sentir no ensino de Administração no Brasil desde o segundo império e a cadeira de direito administrativo, nos cursos de direito, era vista como a parte mais importante no ensino de Administração até os anos 1930 (COELHO, 2006). Após a disseminação dos trabalhos de Frederick Taylor, Henri Ford e Henry Fayol e sua peculiar apropriação no Brasil (ZANETTI e VARGAS, 2007), os cursos de Engenharia passaram a abordar questões administrativas (COELHO, 2006; SILVA, 1958). Embora cursos de Engenharia tratassem de assuntos relacionados à Economia desde a década de 1860, foi a partir dos anos 1930 que incluíram disciplinas como Teoria Econômica formal e Econometria (SANSON, 2004, p. 2).

A partir de 1931, o governo de Getúlio Vargas estabeleceu o curso superior de Administração e Finanças, que poderia ser frequentado pelos egressos do ensino comercial. A ampliação do tamanho do Estado e da atuação do Governo Federal em conjunto com transformações na economia evidenciava a necessidade de capacitar pessoal para levar adiante os negócios públicos e privados. A reorganização do Estado brasileiro centralizou decisões e fortaleceu a unidade nacional em detrimento do aspecto fragmentário que assumia a federação durante a Primeira República (GRAHAM, 1965; COELHO, 2006). A preocupação com a qualificação de uma elite no setor público se fortaleceu durante o governo de Getúlio Vargas, ainda que seja controversa a noção de ele ter trazido mudanças ao status quo. Essas reformas eram marcadas pela tônica da racionalização da gestão do Estado, que adquiria importância crescente no cotidiano do Brasil.

O "deslocamento do centro dinâmico da economia brasileira" [...] para um sistema industrial, trazendo à tona o processo de urbanização, impeliu o Estado para investimentos na indústria de base, 
na infraestrutura de comunicações, transporte e energia e nas políticas sociais. Para se desincumbir destes encargos - residuais ou inexistentes anteriormente -, seguiram-se a criação de ministérios, autarquias e sociedades de economia mista, transformando as feições da administração pública para o fomento do desenvolvimento econômico-social. No âmago desse desponte do capitalismo industrial no país e da consequente (re)estruturação e expansão estatal é que a ciência da administração começou a ganhar espaço, importância e status como atividade profissional e campo de ensino e pesquisa (COELHO, 2006, p. 14).

A criação do Instituto de Desenvolvimento da Organização Racional do Trabalho (Idort), em 1931, e do Departamento de Administração do Setor Público (Dasp), em 1938, está relacionada ao novo papel que a Administração científica de bases tayloristas, ou 'Administração racional', ganhava na sociedade (NICOLINI, 2003; VIZEU, 2008). O Idort promovia a racionalização em todos os âmbitos da vida social e individual, enquanto o Dasp, entre outras funções, concentrava-se em racionalizar o serviço público e promover a meritocracia no Estado (SPIANDORELLO, 2008; COELHO, 2006).

O enfoque tecnicista e burocrático sobre a Administração Pública entre as décadas de 1930 e 1950 (KEINERT, 2000 ) reforçava o ideário da racionalização e baseava-se na importância da distribuição de tarefas e responsabilidades. Também na administração privada, as ideias de Taylor e Ford se espalhavam no Brasil. Além da pressão advinda dos novos formatos organizacionais que se desenvolveram tanto no setor público quanto no privado, outro aspecto permite compreender a difusão das ideias de autores estadunidenses no Brasil e da administração à americana. Ele pode ser inferido a partir das semelhanças com o cenário traçado por Shenhav e Weitz (2000). Conflitos, por vezes latentes, por vezes explícitos, entre empresários e trabalhadores, além das mudanças na configuração socioeconômica das elites do país estimulava a busca por soluções 'racionais'. Os enfrentamentos eram reforçados pelo aumento da população urbana e operária, que já havia participado de vários levantes no Brasil desde o início do século XX (LINHARES, 1977; FAUSTO, 1974).

Assim, o Brasil passava por um turbulento ambiente social e econômico (SPIANDORELLO, 2008). Os embates entre capitalistas e trabalhadores impulsionaram a busca por teorias que permitissem eliminar ou atenuar tais conflitos. A noção de organização racional da sociedade emergiu como ponto importante para a 'modernização' do país e como possível mediação de conflitos entre capital e trabalho.

A racionalização tende a coincidir com a caracterização das formas de organizar presentes nos países centrais do Ocidente (MIGNOLO, 2005). Assim, as medidas adotadas no intuito de criar uma 'sociedade racional', espelhando países considerados 'desenvolvidos', contribuem para a adoção de modelos 'estrangeiros' de Administração visando ao desenvolvimento brasileiro. A ideia de que há uma trajetória inflexível em direção ao 'desenvolvimento' e à modernidade acompanhava as discussões sobre os rumos que os países da América Latina deveriam tomar. Essa perspectiva permeou o desenvolvimento dos cursos de Administração no Brasil.

Contudo, reitera-se que antes do modelo estadunidense se tornar referência para cursos superiores em Administração, já havia desenvolvimentos no campo do ensino da matéria no Brasil. O primeiro curso superior a tratar diretamente da Administração - e não como um subtópico, como era o caso das Engenharias e do Direito - foi o curso de Administração e Finanças. Regulado por meio do Decreto n. 20.158, de 30 de junho de 1931 (BRASIL, 1931), esse curso se estabeleceu, na maioria das vezes, em escolas anexas às Escolas de Comércio e contava com parte de seus professores oriundos de escolas de Direito. Espelhava um ensino vocacional de temas relacionados à Administração, à Economia e à Contabilidade, embora, muitas vezes, emulasse teóricos da 'administração científica'.

Os egressos dos cursos de Administração e Finanças eram diplomados: "aos que concluírem o Curso Superior de Administração e Finanças será conferido o diploma de bacharel em ciências econômicas, e o título de doutor em ciências econômicas, se defenderem tese perante a respectiva congregação" (BRASIL, 1931). Todavia, as características desses cursos eram distintas dos bacharelados contemporâneos. Na maioria das vezes, partia-se de uma abordagem prática e sem sofisticação acadêmica, em um curso que não tinha status universitário e não era frequentado pelas elites. A experiência com o curso de Administração e Finanças formalizou o Ensino Superior dedicado principalmente a matérias administrativas. Por força de Decreto-Lei n. 6.141, de 28 de dezembro de 1943, o curso passa da jurisdição da Diretoria do Ensino Comercial para a da Diretoria do Ensino Superior do Ministério da Educação, o que mostrava a mudança de status que se buscava dar aos egressos (PINTO, 1963). 
Posteriormente, o curso de Administração e Finanças foi extinto pelo Decreto-Lei n. 7.988, de 22 de setembro de 1945 . Ao mesmo tempo foi regulamentado "o ensino superior de ciências econômicas e de ciências contábeis e atuariais" (BRASIL, 1945). No caso da FACE/UFMG:

A integração do curso na categoria do ensino superior, com o acréscimo de exigências e fiscalização mais rigorosa levou os proprietários das duas referidas Faculdades a cogitar da sua extinção ou transferência para terceiros. [...] A 5 de março de 1945 foi organizada, sob a forma de sociedade civil, sem caráter lucrativo [...] a FACULDADE DE CIÊNCIAS ECONÔMICAS E ADMINISTRATIVAS DE MINAS GERAIS, mediante a incorporação da antiga Faculdade de Ciências Econômicas e Administrativas de Belo Horizonte, anexa à Escola Técnica de Comércio de Minas Gerais, e o absorvimento da Faculdade de Economia, Administração e Finanças, anexa à Escola Técnica de Comércio de Belo Horizonte (PINTO, 1963, p. 17-18, grifo do autor).

As áreas de Contabilidade, Atuária e Economia foram separadas apenas em 1945 (SANSON, 2004). Até aquele momento, os diplomas concedidos eram em Economia, o que pode ser observado por meio das leis de 1931 e 1945 que regulamentavam a profissão (BRASIL, 1931; 1945). Nesse sentido, os cursos de Contabilidade, Atuária e Administração se desenvolveram sobre a área de atuação que anteriormente era dominada pela Economia, o que gerou alguns conflitos com associações de classe dos economistas, que almejavam a incorporação de todas as especializações sob o mesmo guarda-chuva (BARROS, ALCADIPANI e BERTERO, 2015; COELHO e NICOLINI, 2014).

A extinção do curso em 1945 (BRASIL, 1945) ensejou a reorganização das faculdades e vários estabelecimentos de ensino passaram a oferecer bacharelados em Economia e Ciências Contábeis (PAULA, 1991). Como mostra Yvon Leite de Magalhães Pinto (1963), ex-diretor da FACE/UFMG, a nova regulamentação forçou mudanças institucionais. Como outras escolas que ensinam Administração, Contabilidade e Economia, a Faculdade de Ciências Econômicas e Administrativas de Minas Gerais surgiu como estabelecimento anexo à Escola Técnica de Comércio de Minas Gerais, em 1941, incorporando seus cursos e os de outra Escola de Comércio em 1945. Pinto (1963) afirma que a reestruturação que extinguiu os cursos de Administração e Finanças foi fundamental para decidir a criação da nova escola, sendo o curso existente na FACE/UFMG repensado à luz das diretrizes que passaram a vigorar por recomendação do Ministério da Educação e Cultura (BRASIL, 1945). A partir das diretrizes estabelecidas pelo Decreto-Lei n. 7.988/1945 (BRASIL, 1945), as matérias que estavam ligadas ao ensino de Administração passaram ao domínio dos cursos de Contabilidade, enquanto nos moldes estadunidenses os cursos de Economia concentraram disciplinas mais teóricas e de métodos quantitativos (SANSON e NICOLAU, 2006). Posteriormente, tal divisão propiciou aos administradores uma formação mais tecnicista do que aquela oferecida aos economistas. O curso de Administração se aproximava das disciplinas práticas que ficaram sob a égide dos cursos de Contabilidade.

Em decorrência do vínculo originário ao curso superior de Administração e Finanças, parte dos primeiros cursos nas áreas de Contabilidade e Economia era herdeira de cursos comerciais ou com eles estabeleceram relações de proximidade (COELHO, 2006; COELHO e NICOLINI, 2014). Contudo, essa primeira tentativa de um curso de Administração de nível superior foi um fracasso (COELHO, 2006). Silva (1958, p. 20) entende que o curso de Administração e Finanças não havia conseguido arregimentar alunos, razão maior para sua extinção em 1945:

O Curso Superior de Administração e Finanças apresentava algumas características estranhas, até pilhéricas. Embora chamado de curso superior na lei, não era reconhecido como tal pelo Ministério da Educação. Era de Administração e Finanças, mas o diploma conferido aos que o concluíam era de bacharel em economia. Além disso, exigia dos candidatos, como requisito indispensável, a posse do diploma de perito-contador ou de atuário. Em última análise, era um dispositivo para transformar, legalmente, perito-contadores e atuários em economistas via Administração e Finanças.

Apesar do insucesso, o curso de Administração e Finanças impulsionou a articulação de escolas que posteriormente se proporiam a ministrar cursos específicos relacionados a cada uma das áreas. O Ensino Superior em Administração só se estabeleceu quando houve o deslocamento do modelo europeu para o estadunidense, voltado ao ensino de técnicas administrativas (COELHO, 2006). Essa distinção, inclusive, foi importante para que a Fundação Getulio Vargas (FGV) rejeitasse o apoio de Emílio Matarazzo em favor da aproximação maior com o modelo estadunidense (ALCADIPANI e BERTERO, 2014). ESsa mudança contribuiu para a criação dos primeiros cursos superiores em Administração. 
Naquele momento a ideia de que o ofício de administrador poderia ser aprendido ganhou força. A criação "dos cursos de administração, na sociedade brasileira, iria contribuir para o estabelecimento de uma clivagem entre os 'autodidatas' e os 'administradores profissionais'” (MARTINS, 1989, p. 665), trazendo mudanças significativas para essa área de atuação. A construção de espaços que poderiam e deveriam ser ocupados por profissionais formados em cursos superiores foi relevante para as mudanças que se efetivaram e consolidaram depois da metade do século XX.

A intensificação do uso de modelos estrangeiros na estruturação das organizações brasileiras e do ensino de Administração tornou-se mais forte em 1948, quando representantes da FGV visitaram diversos cursos de Administração Pública sediados em universidades norte-americanas, como resultado da cooperação técnica Brasil-Estados Unidos estabelecida após o fim da Segunda Guerra (NICOLINI, 2003, p. 46).

Até o fim da década de 1950, apenas a Escola Superior de Administração e Negócios (ESAN), a Escola Brasileira de Administração Pública (EBAP), a FACE/UFMG e a Escola de Administração de Empresas de São Paulo (EAESP) contavam com cursos destinados à formação de administradores em nível superior (MACHADO, 1966). Contudo, apenas os cursos das três últimas instituições estavam em conformidade com as normas do Ensino Superior vigente à época. Um dos óbices à propagação dos cursos era o fato da profissão não ser ainda regulada pelo Governo Federal, o que aconteceu em 1965. Além disso, eram registradas reticências quanto à necessidade de formação, principalmente para o administrador de empresas. Nesse sentido, a expansão inicial de cursos superiores em Administração enfoca a área pública, a fim de atender às demandas de um Estado que se queria indutor do desenvolvimento (COELHO e NICOLINI, 2014).

Com a ascensão de graduações em Administração, Economia e Contabilidade, as escolas comerciais perderam parte de sua justificativa de existência, já que os temas que eram abarcados em seus cursos passaram a ser discutidos em mais profundidade nos cursos superiores. Pode-se afirmar que se o curso superior de Administração e Finanças era apêndice dos cursos técnicos de comércio já existentes (COELHO e NICOLINI, 2014), também serviu para forçar a reorganização de estabelecimentos de ensino que assumiram papel de destaque na formação de bacharéis e na produção de conhecimento. Além disso, ao ser obscurecido pelos cursos superiores, os cursos técnicos, ainda que pudessem oferecer uma formação com potencial relevância na trajetória de vida dos egressos, foram desaparecendo gradativamente.

Considera-se válido apontar um acréscimo a uma interpretação oferecida por Coelho e Nicolini (2013). Os autores atestam que o Ensino Superior em Administração era dominado pelos cursos de Administração Pública, porque as empresas brasileiras, usualmente, eram geridas pelos proprietários. Conquanto tal elemento seja de fato importante, acrescenta-se, a partir do cenário delineado, a existência de milhares de estudantes de cursos de comércio que atenderiam à demanda existente por gestores de nível intermediário com formação específica nas empresas.

\section{CONSIDERAÇÕES FINAIS}

Este artigo discutiu o desenvolvimento das escolas de Comércio brasileiras, apontando suas relações com as primeiras modalidades de cursos superiores brasileiros, nos quais se dava o ensino de saberes ligados aos cursos de Administração, Economia e Contabilidade: os cursos superiores de Administração e Finanças. Assim, foi enfatizada a importância desses estabelecimentos de ensino e desse curso na criação das escolas que posteriormente passaram a contar com o Ensino Superior, como é o caso da FACE/UFMG.

As experiências que visavam a formar profissionais em um momento de transformação da sociedade brasileira no qual a economia brasileira se diversificava e a urbanização se acentuava fracassaram com o curso superior de Administração e Finanças. Esse curso foi substituído em 1945 pelos cursos superiores de Economia, Contabilidade e Atuária, que abarcavam os assuntos que posteriormente seriam abrangidos pelos cursos superiores em Administração.

A análise da literatura permitiu perceber que, por ser um tema relativamente inexplorado, há diversos caminhos possíveis para aprofundamentos futuros. Este texto delineia um panorama geral e elucida elementos do processo de estabelecimento da Administração no país, mas também abre caminhos para pesquisas que porventura possam ter interesse em abordar aspectos específicos do problema discutido. A carência de informações indicou uma lacuna que este texto busca preencher, contribuindo 
com o debate sobre os cursos de Administração no Brasil (FISCHER, 1985; MARTINS, 1989; SERVA, 1990; BERTERO, 2006; COELHO, 2006; SPIANDORELLO, 2008; BARROS e CARRIERI, 2013; ALCADIPANI e BERTERO, 2014; COOKE e ALCADIPANI, 2015).

Ressaltou-se a importância de discutir o passado da Administração no Brasil em um período que antecede os primeiros cursos superiores. Esse esforço se junta ao de outros autores, no intuito de explicitar quem eram os agentes que contribuíram para a disseminação de saberes administrativos (BERTERO, 2006; ZANETTI e VARGAS, 2007; VIZEU, 2008; BARROS, CRUZ, XAVIER et al., 2011). Quando novas modalidades de ensino passaram a se estabelecer, grandes mudanças foram implantadas, mas elas certamente não eliminaram as condições anteriores e foram afetadas por elas.

Nesse mesmo sentido, observa-se que o modelo estadunidense desembarca no país em um momento em que já havia uma estrutura que contribuiu com sua disseminação e que também pode ter afetado sua adaptação. Essa observação é coerente com as discussões de Kipping, Üsdikem e Puig (2004) e Kipping, Üsdikem e Engwall (2008), bem como os argumentos de Locke (1989). Reitera-se, ainda, que as primeiras escolas, professores e demais profissionais que atuavam no campo que viria a ser denominado Administração - que agora passa por nova diferenciação entre a Administração (de empresas) e Administração Pública - preexistiam aos acordos entre Brasil e Estados Unidos que colaboraram na disseminação do Ensino Superior no País (ALCADIPANI e BERTERO, 2014; BARROS e CARRIERI, 2013). Reconhecer que esses acordos e o desenvolvimento dos cursos aconteceram em um cenário em que outros atores estavam estabelecidos é um caminho para entender melhor o desenvolvimento e a situação atual da Administração no país

Assim, este artigo contribui com a discussão, delineando um quadro sobre os estabelecimentos de ensino que existiam antes dos cursos superiores serem criados. Evidencia, ainda, elementos contextuais que permitem compreender melhor aspectos 'nativos' do ensino em Administração.

Contudo, cabe apontar os limites deste trabalho, na medida em que não se debruçou sobre estudos mais específicos acerca dos cursos que existiram. Abre-se, assim, uma porta para outras pesquisas que, por exemplo, analisem os currículos dos cursos de Comércio comparativamente aos dos primeiros cursos superiores em Administração. Seria relevante verificar em que medida os cursos das escolas de Comércio se assemelhavam ou não aos cursos de Administração Pública e de Empresas, dado que em seus primórdios ambos tinham um apelo muito grande para a prática e para a vocação. Entender a dinâmica do desenvolvimento e fechamento de escolas específicas pode trazer contribuições valiosas, bem como discutir como se compreendia o ensino comercial vis-à-vis as outras modalidades existentes no século XX. Nesse sentido, as pesquisas em arquivos permitiriam contribuições com área ao discutir o desenvolvimento da Administração no Brasil. 


\section{REFERÊNCIAS}

ALCADIPANI, R.; BERTERO, C. O. Guerra Fria e ensino do management no Brasil: o caso da FGV-EAESP. Revista de Administração de Empresas, v. 52, n. 3, p. 284-299, 2012.

ALCADIPANI, R.; BERTERO, C. O. Uma escola americana no ultramar? Uma historiografia da EAESP. Revista de Administração de Empresas, v. 54, n. 2, p. 154-169, 2014.

ALCADIPANI, R.; CALDAS, M. P. Americanizing Brazilian management. Critical Perspectives on International Business, v. $8, \mathrm{n}$. 1, p. 37-55, 2012.

ANDREOTTI, A. L. A Administração Escolar na Era Vargas e no Nacional Desenvolvimentismo. Revista HISTEDBR On-line, Campinas, n. especial, p. 102-234, ago. 2006.

BARROS, A.; ALCADIPANI, R.; BERTERO, C. O. A criação da graduação em Administração na UFRGS: a influência dos Estados Unidos e da FGV. In: COLÓQUIO DE EPISTEMOLOGIA E SOCIOLOGIA DA CIÊNCIA DA ADMINISTRAÇÃO, 5., 2015, Florianópolis. Anais... Florianópolis: [s.n], 2015.

BARROS, A; CARRIERI, A. D. P. Ensino Superior em administração entre os anos 1940 e 1950: uma discussão a partir dos acordos de cooperação Brasil-Estados Unidos. Cad. EBAPE.BR, v. 11, n. 2, p. 256-273, 2013.

BARROS, A. et al. Apropriação dos saberes administrativos: um olhar alternativo sobre o desenvolvimento da área. Revista de Administração da Mackenzie, v. 12, n. 5, p. 43-67, 2011.

COOKE, B.; ALCADIPANI, R. Towards a global history of management education: the case of the Ford foundation and the São Paulo School of Business Administration, Brazil. Academy of Management Learning \& Education, v. 14, n. 4, p. 482-499, 2015.

COSTA, A. M.; BARROS, D. F.; MARTINS, P. E. M. Perspectiva histórica em administração: novos objetos, novos problemas, novas abordagens. Revista de Administração de Empresas, v. 50, n. 3, p. 288-299, 2010.

FERREIRA, F. V. Potencialidades da análise histórica nos estudos organizacionais brasileiros. Revista de Administração de Empresas, v. 50, n. 1, p. 37-47, 2010.

FISCHER, T. O ensino de Administração Pública no Brasil: da tutela estrangeira à autonomia necessária. In: REUNIÃO NACIONAL DA ANPAD, 1985, Belo Horizonte. Anais... Florianópolis: Ed. UFSC, 1985. $165-170 \mathrm{p}$.

BERTERO, C. O. Pesquisa e ensino em administração. São Paulo: Thompson, 2006.

BRASIL. Decreto n. 20.158, de 30 de junho de 1931. 1931. Disponível em: <http://www2.camara.gov.br/legin/fed/decret/1930-1939/ decreto-20158-30-junho-1931-536778-republicacao-81246-pe.html>. Acesso em: 14 out. 2014.

BRASIL. Decreto-Lei n. 6.141, de 28 de dezembro de 1943. Lei Orgânica do Ensino Comercial. 1943. Disponível em: <http://www6.
senado.gov.br/legislacao/ListaPublicacoes.action ?id=6717>. Acesso em: 14 out. 2014

BRASIL. Decreto-Lei n. 7.988, de 22 setembro de 1945. Disponível em: <http://www6.senado.gov.br/legislacao/ListaPublicacoes. action?id=27880 $>$. Acesso em: 14 out. 2014.

BRASIL. Lei n. 4.024, de 20 de dezembro de 1961. 1961. Lei de Diretrizes e Bases. Disponível em: <http://www6.senado.gov.br/legislacao/ListaPublicacoes.action?id=102346>. Acesso em: 14 out. 2014.

BRASIL. Decreto n. 61.943, de 22 de dezembro de 1967. Dispõe sobre a regulamentação do exercício da profissão de Técnico de Administração e a constituição ao Conselho Federal de Técnicos de Administração, de acordo com a Lei n. 4.769, de 9 de Setembro de 1965, e dá outras providências. 1967. Disponível em: <http://www. planalto.gov.br/cCivil_03/decreto/Antigos/D61934.htm>. Acesso em: 2 jan. 2017.

BRITO, S. H. A. A educação no projeto nacionalista do primeiro governo Vargas (1930-1945). In: LOMBARDI, J. C. (Org.). Navegando na história da educação brasileira. Campinas, SP: Unicamp, 2006. v. 1. 1-24 p.

CANALI, H. H. B. A trajetória da formação profissional no Brasil e os desafios da construção de um Ensino Médio integrado à educação profissional. In: SIMPÓSIO SOBRE TRABALHO E EDUCAÇÃO, 5., Belo Horizonte, 2009. Anais... Belo Horizonte: Universidade Federal de Minas Gerais, 2009. Disponível em: <http://www.portal.fae.ufmg.br/ simposionete old2/sites/default/files/CANALI,Heloisa.pdf>. Acesso em: 14 out. 2014.

CASTRO, N. J. As origens da Faculdade Nacional de Ciências Econômicas da Universidade do Brasil. Rio de Janeiro: FEA/UFRJ, 1991. (Texto para discussão, mimeografado).

CINTRA, E. P. Cursos comerciais em colégio católico feminino: uma aparente contradição? Curitiba, 1940-1950. Educar, n. 33, p. 235252, 2009.

CLARK, P.; ROWLISON, M. The treatment of history in organization studies: towards an 'historic turn'? Business History, v. 46, n. 3, p. 331-352, 2004.

COELHO, F. Educação superior, formação de administradores e setor público: um estudo sobre o ensino de administração pública - em nível de graduação - no Brasil. 151f. Tese (Doutorado em Administração) - Escola de Administração de Empresas de São Paulo, Fundação Getulio Vargas, São Paulo, 2006.

COELHO, F.; NICOLINI, A. M. Do auge à retração: análise de um dos estágios de construção do ensino de Administração Pública no Brasil (1966-1982). Organizações \& Sociedade, v. 20, n. 66, p. 403-422, 2013.

COELHO, F.; NICOLINI, A. M. Revisitando as origens do ensino de graduação em administração pública no Brasil (1854-1952). Rev. Adm. Pública, v. 48, n. 2, p. 367-388, 2014.

FAUSTO, B. Conflito social na república oligárquica: a greve de 1917. Estudos Cebrap, São Paulo, n. 10, p. 79-109, out./dez. 1974.

FISCHER, T. M. O ensino de administração pública no Brasil: da tutela estrangeira à autonomia necessária. In: REUNIÃO ANUAL DA ANPAD, 
2., 1985, Florianópolis. Anais... Florianópolis, Universidade Federal de Santa Catarina, 1985. 165-170 p.

FOUCAULT, M. A arqueologia do saber. Rio de Janeiro: Forense Universitária, 2008.

FRENKEL, M. The Americanization of the antimanagerialist alternative in Israel: how foreign experts retheorized and disarmed workers, 1950-1970. International Studies of Management \& Organization, v. 38, n. 4, p. 17-37, 2009.

FRENKEL, M.; SHENHAV, Y. From Americanization to colonization: the diffusion of productivity models revisited. Organization Studies, v. 24, n. 9, p. 1537-1561, 2003.

GOMES JÚNIOR, A. C. Breves apontamentos da trajetória do ensino profissional comercial e o pensamento dos clássicos Adam Smith e Jean-Jacques Rousseau. Empreendedorismo, Gestão e Negócios, v. 2, n. 2, p. 151-161, 2013.

GRAHAM, L. S. Clash between formalism and reality in the Brazilian civil service. 429f. Thesis (Ph.D. in Philosophy) - University of Florida, 1965.

IBARRA-COLADO, E. Organization studies and epistemic coloniality in Latin America: thinking otherness from the margins. Organization, v. 13, n. 4 , p. $463-488,2006$.

KEINERT, T. M. M. O que é Administração Pública no Brasil. In: ENCONTRO ANUAL DA ANPAD, XXIV. Florianópolis, 2000. Anais... Florianópolis: ANPAD, 2000. 148-159 p.

KEINERT, T. M. M. Os paradigmas da administração pública no Brasil. Revista de Administração de Empresas, v. 34, n. 3, p. 41-48, 1994.

KIPPING, M.; ENGWALL, L; ÜSDIKEM, B. The transfer of management knowledge to peripheral countries. International Studies of Management and Organization, v. 38, n. 3, p. 3-16, 2008.

KIPPING, M.; ÜSDIKEN, B. History in organization and management theory: more than meets the eye. The Academy of Management Annals, v. 8, n. 1, p. 535-588, 2014.

KIPPING, M.; ÜSDIKEN, B.; PUIG, N. Imitation, tension and hybridization: multiple "Americanizations" of management education in Mediterranean Europe. Journal of Management Inquiry, v. 13, n. 2, p. 98-108, 2004.

LINHARES, H. Contribuição à história das lutas operárias no Brasil. São Paulo; Alfa-Omega; 1977.

LOCKE, R. R. Management and higher education since 1940. The influence of America and Japan on West Germany, Great Britain and France. Cambridge/New York: Cambridge University Press, 1989.

MACHADO, M. B. O Ensino de Administração Pública no Brasil. Rio de Janeiro: Editora da Fundação Getúlio Vargas, 1966.

MARTINS, C. B. Surgimento e expansão dos cursos de administração no Brasil. Ciência e Cultura, v. 41, n. 7, p. 663-676, 1989.

MIGNOLO, W. D. The idea of Latin America. London: Blackwell, 2005.
NICOLINI, A. M. Qual será o futuro das fábricas de administradores? Revista de Administração de Empresas, v. 43, n. 2, p. 44-54, 2003.

PAULA, J. A. Passado e presente de uma instituição: memória da Faculdade de Ciências Econômicas/UFMG. Belo Horizonte: UFMG/ FACE/CEDEPLAR, 1991.

PELEIAS, I. R. et al. Evolução do ensino de contabilidade no Brasil: uma análise histórica. Revista de Contabilidade e Finanças, v. 18, n. Edição especial, p. 19-32, 2007.

PERES, F. A. Alguns apontamentos sobre o ensino comercial no Brasil. Disponível em: <http://www.histedbr.fae.unicamp.br/acer_histedbr/ encontro/encontro1/trab_pdf/t_fernando\%20antonio\%20peres. pdf>. Acesso em: 13 out. 2014.

PETINELLI-SOUZA, S. Constituição e formação do sujeito administrador. Administração: Ensino e Pesquisa, v. 14, n. 3, p. 453-483, 2013.

PINTO, Y. L. M. O movimento “estudantil” de 1960. Belo Horizonte: Santa Maria, 1963.

ROWLINSON, M. Management \& organizational history: the continuing historic turn. Management \& Organizational History, v. 8, n. 4, p. 327-328, 2013.

ROWLINSON, M.; JACQUES, R.; BOOTH, C. Critical management and organizational history. In: ALVESSON, M.; BRIDGMAN, T.; WILLMOTT, $\mathrm{H}$. (Eds.). The Oxford handbook of critical management studies. Oxford: Oxford University Press, 2009. 286-304 p.

SANSON, J. R. De guarda-livros a economistas. Atualidade Econômica, v. 16, n. 47, p. 1-5, 2004.

SANSON, J. R.; NICOLAU, J. A. Do ensino de técnicas comerciais ao ensino de Economia em Santa Catarina. Análise, v. 17, n. 2, p. $297-$ 312, 2006.

SERVA, M. Contribuições para uma teoria organizacional brasileira. Rev. Adm. Pública, v. 24, n. 2, p. 10-21, 1990.

SHENHAV, Y.; WEITZ, E. The Roots of Uncertainty in Organization Theory: a historical constructivist analysis. Organization, v. 7, n. 3, p. 373-401, 2000.

SILVA, B. Gênesis do ensino de Administração Pública no Brasil. Cadernos de Administração Pública, v. 49, p. 1-42, 1958.

SOUZA, N. J. O economista: a história da profissão no Brasil. Análise, v. 17, n. 2, p. 377-383, 2006.

SPIANDORELLO, S. C. Fragmentos da constituição da profissão de administrador (1931-1966). 211f. Dissertação (Mestrado em Administração), Universidade São Francisco, Itatiba, 2008.

ÜSDIKEN, B. Importing theories of management and organization: the case of Turkish academia. International Studies of Management \& Organizations, v. 26, n. 3, p. 33-46, 1997.

ÜSDIKEN, B. Exporting managerial knowledge to the outpost: penetration of "human relations" into Turkish academia, 1950-1965. Management Learning, v. 35, n. 3, p. 255-270, 2004. 
ÜSDIKEN, B.; ÇETIN, D. From betriebswirtschaftslehre to human relations: Turkish management literature before and after the Second World War. Business History, v. 43, n. 2, p. 99-124, 2001.

ÜSDIKEN, B.; KIESER, A. Introduction: history in organization studies. Business History, v. 46, n. 3, p. 321-330, 2004.

VIZEU, F. Management no Brasil em Perspectiva Histórica: o projeto do IDORT nas décadas de 1930 e 1940. Tese (Doutorado em Administração). EAESP/FGV. São Paulo: 2008.
WANDERLEY, S. Desenvolviment(ism)o, descolonialidade e a geo-história da administração no Brasil: a atuação da CEPAL e do ISEB como instituições de ensino e pesquisa em nível de pós-graduação. 322 f. Tese (Doutorado em Administração) - Escola Brasileira de Administração Pública e de Empresas, Fundação Getulio Vargas, Rio de Janeiro, 2015.

ZANETTI, A.; VARGAS, J. T. Taylorismo e fordismo na indústria paulista: o empresariado e os projetos de organização racional do trabalho, 1920-1940. São Paulo: Humanista, 2007. 